\title{
ЛИТЕРАТУРОВЕДЕНИЕ
}

\author{
А.М. Багиров
}

\section{СОВРЕМЕННЫЕ ПРОБЛЕМЫ \\ ХУДОЖЕСТВЕННОГО ПЕРЕВОДА (на материале русско-азербайджанского направления)}

Аннотация. Объектом научного исследования в данной статье являются принципы и проблемы современного художественного перевода на основе фактических материалов русско-азербайджанского литературного направления. Предмет исследования - возникновение и этапы развития советского переводоведения, в том числе, появление в советский период в азербайджанском литературоведении теории перевода, как отдельного научного аспекта. Также автор уделяет большое внимание в глобализирующемся мире анализу духовно-эстетических функций художественного текста во благо моральных потребностей человечества. Главная цель исследования состоит в том, чтобы подчеркнуть бесценный вклад взаимопереводов, в достижении взаимопонимания, диалога, сближения, сплочения двух по духу близких народов - русского и азербайджанского. Исследование, результаты которого представлены в данной статье, проводилось с использованием таких методов, как аналитико-культурологический, исторический и сравнительно-сопоставительный. Богатый арсенал художественного перевода русско-азербайджанского литературного направления советского периода последние годы оценивается, как правило, негативно.

Научная новизна работы заключается в том, что в результате скрупулёзно подробного анализа объективно оценивается художественный взаимоперевод азербайджанских и русских авторов на русский и азербайджанский языки, обобщается позитивная картина в области русско-азербайджанской литературной взаимосвязи. В этой статье убедительно обосновывается взаимовлияние и востребованность взаимоперевода не только советского и постсоветского периода, но, и в наши дни, а также и в будущем.

Ключевые слова: проблемы перевода, межнациональные отношения, теория перевода, художественный текст, культурные связи, адекватность текста, национальное своеобразие, подстрочные переводы, эквивалентность перевода, переводоведение.

Abstract. The object of the present research is the principles and problems of contemporary literary translation based on the analysis of actual Russian-Azerbaijanian translations. The subject of the research is the origin and stages of the development of Soviet translation studies including the translation theory as an independent scientific concept created in Azerbaijanian literary studies during the Soviet period. The author also pays much attention to the analysis of spiritual and aesthetic functions of a literary text aimed at promoting human morals in the globalizing world. The main purpose of the research is to underline a distinguished contribution of translation to achieving mutual understanding, dialogue and better cross-cultural communication of the two nations that are quite close to each other mentally, Russian and Azerbaijanian. The research was carried out using such methods as analytical-cultural, historical and comparative. Important tools of Russian-Azerbaijanian literary translations of the Soviet period usually receive negative comments. The novelty of the present research is caused by the fact that as a result of thorough analysis, the author provides an objective evaluation of literary translations made by Russian and Azerbaijanian authors, and underlines the positive influence of RussianAzerbaijanian literary relations. In his article Bagirov proves the mutual contributions and emphasizes the need for such translations not only during the Soviet or post-Soviet periods but also today and in the future.

Key words: translation studies, translation equivalence, word-for-word translation, nativism (national peculiarities), text adequacy, cultural relations, literary text, translation theory, cross-cultural communication, translation problems.

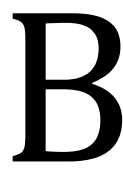

опрос о принципах и проблемах художественного перевода, в том числе русскоазербайджанского направления, широко разработан в литературоведении. Извест- ное крылатое высказывание о роли переводческой деятельности великого немецкого поэта-мыслителя И.В. Гёте (1749-1832) остаётся актуальным на все времена: «Что бы ни говорилось о неудовлет- 
ворительности переводческого труда, он всегда был и будет одним из важнейших и достойнейших дел, связывающих воедино Вселенную» [1, с. 19].

В глобализирующем мире стремление людей к культурно-духовному единению и консолидации усиливается многократно и в этом процессе особенная роль принадлежит взаимовлиянию национальных культур. А взаимовлияние происходит, несомненно, и благодаря переводам, которые служат самой высокой дружбе не только между литературами, но и в целом между народами. Основным средством для достижения этой высокой и благородной цели, в своё время, Максим Горький видел, именно, «в хороших переводах» [2, с. 296]. В самом деле, в советский период основательная, широкая и системная постановка переводческого дела, являлась основой формирования единой многонациональной советской литературы, и искусство перевода достигло в стране такого расцвета, что её, по праву, в мире называли «переводной державой». Советскому читателю была доступна не только основная сокровищница мировой литературы, но и достижения классической и современной литератур союзных республик в переводе на русский язык.

Естественно, с развитием искусства перевода создавалась и развивалась новая теоретическая дисциплина в советском литературоведении - переводоведение. Удивительно, что впервые обобщил достижения советской школы художественного перевода известный поэт и переводчик К.И. Чуковский (1882-1969) ещё в 30-е гг. в своих теоретических статьях. И неоднократно дополняя, расширяя их своими новыми исследованиями, наблюдениями, наконец-то, он в 1968 г. в издательстве «Советский писатель» выпустил свою непревзойдённую, объёмную книгу о теории перевода «Высокое искусство» [3]. Известный русский литературовед А.В. Фёдоров (1906-1997) в своём известном многолетнем научном труде «Основа общей теории перевода», изданном в 1968 г. в Москве в издательстве «Наука», обстоятельно разработал научно-философскую и аналитико-методологическую основу художественного перевода [4]. А также, значительный вклад внесли в разработку проблем и теории перевода своими научными работами И.А. Кашкин, В.М. Россельс, П.М. Топер, М.А. Лозинский и другие российские учёные.

Проблемы перевода, его роль в культурном развитии народа всегда были предметом пристального внимания и интереса видных азербайджанских литературоведов старшего поколения. Выдающийся критик и литературовед, академик Мамед Ариф с удовлетворением отметил: «Есть такие выдающиеся представители азербайджанской советской литературы, что после перевода на русский язык их произведения не только переводились на языки советских народов, но и на многие зарубежные языки» [5, с. 341]. А также интересными статьями по важным вопросам развития художественного перевода в Азербайджане выступили Микаил Рафили, Азиз Шариф, Азиз Мирахмедов, Акбер Агаев, Бекир Набиев, Джалал Мамедов и др. Кстати, переводоведение в азербайджанском литературоведении является сравнительно молодым научным направлением.

Вопросы перевода с русского на азербайджанский язык и теоретические обобщения перевода освещены в кандидатской диссертации Джумшуда Азимова [6]; некоторые проблемы перевода стихотворений азербайджанских поэтесс - в работе Саиды Гусейновой [7]; вопросы перевода на русский язык современной азербайджанской поэзии в целом - в исследовании Назлы Бабаевой [8]. Художественные переводы как форма межнациональной связи литературы на материале русского и азербайджанского языка подробно рассмотрены в диссертации Рафика Новрузова [9]. Лингвистический аспект проблемы перевода был обстоятельно разработан и в докторской диссертации Байрама Таирбекова [10]. Теоретико-эстетические принципы создания азербайджанской советской поэзии на основе богатого художественного литературного материала были исследованы в некоторых фундаментальных работах известной исследовательницы в области азербайджанско-русских литературных взаимосвязей, доктора филологических наук, профессора Фариды Велихановой [11]. В советский период написана масса статей по вопросам перевода, в том числе затрагивающих русско-азербайджанское направление. Важно отметить, что именно советская школа перевода не только выдала высочайшие образцы переводных текстов, зачастую адекватных к оригиналу, но и стала основой для мощной теории художественного переводоведения.

Одной из важных и принципиальных проблем художественного перевода всегда был и остаётся вопрос о том, чего первым долгом необходимо добиваться при переводе: буквальности, эквивалентности - точности, верности оригиналу или адекватности - коммуникативной состоятельности? Буквальный эквивалентный перевод в основном ближе к подстрочному переводу и, соответственно, такой метод перевода трудно считать творческим подходом, ибо конечный результат - переводной текст, как правило, не отвечает требованиям художественного перевода. Бесспорно, единственно приемлемым и верным творческим подходом является адекватность художественного перевода. Этот метод обязывает переводчика подходить к переводимому материалу творчески, находя на переводимом языке адекватов - равнозначных смыслов 
всех нюансов и своеобразия оригинала, передать не буквальный смысл, а содержание, суть текста, наполненное ментальным духом и психологически верным образно-национальным мышлением.

Данная проблема всегда находится в центре внимания многих серьёзных российских исследователей - литературоведов. Известная русская исследовательница И.С. Алексеева в своей монографии «Текст и перевод» чётко определяет некоторые неизбежные проблемы, с которыми в творческом процессе сталкиваются переводчики художественных текстов: «Поскольку художественный текст, созданный в определённое время живёт, затем долго и хранит черты определённой эпохи: поскольку он всегда, связан с литературной средой и её канонами; поскольку он несёт на себе отпечаток творческой индивидуальности, переводчику художественного текста приходится всегда сталкиваться с тремя основными проблемами: передача временной отнесённости текста, передача черт литературного направления, передача индивидуального стиля автора» [12, с. 135].

Эта проблема и сегодня требует в азербайджанском литературоведении весьма серьёзного исследования, именно в аспекте русско-азербайджанских литературных связей и имеются немало существенных теоретических работ азербайджанских литературоведов.

Как известно, в творческом процессе художественного перевода, отдельной проблемой остаётся вопрос национального своеобразия, специфика художественной литературы. В этой связи, национальное своеобразие в поэзии создаёт особенные трудности в процессе её перевода на другой язык. Может ли быть передана на другом языке неповторимая поэтическая прелесть оригинала? Безусловно, это зависит только от умения и таланта поэта-переводчика. По этому поводу известный исследователь теории перевода поэзии Н.Г. Бабаева проводит совершенно верную и точную теоретическую мысль: «Современная азербайджанская поэзия - сложная поэтическая система, в которой органически слились восточно-классические, фольклорные традиции, современные поиски и эксперименты. Переводчику необходимо знать особенности поэтики азербайджанского стиха, уметь отличить традиционно-восточного от новаторского явления. Неумение ориентироваться в прошлом и настоящем переводимой поэзии, в стилистической изощрённости её образов, наносит урон целостному воссозданию на русском языке. Воссоздание национального своеобразия азербайджанской поэзии в русских переводах возможно при особой творческой гибкости переводчика, умеющего проникнуть в содержание оригинала, сохранить само- бытность его образной системы и особенности ритмико-интонационного движения» [8, с. 6].

Общеизвестно, что при переводе на русский язык азербайджанской поэзии создаются дополнительные сложности тем, что особенности поэтики связаны не только с национальным менталитетом, своеобразием, языком, но и с традиционной системой стихосложения. Древняя азербайджанская поэзия в основном создавалась в силлабической стихотворной форме. Начиная с VII в. нашей эры, в классической поэзии доминантной стихотворной формой стала поэтическая метрика «аруз» арабского происхождения, а с XX в. появился совершенно новый и неожиданно для азербайджанской поэзии стихотворный жанр - свободный стих, или, по выражению некоторых литературоведов - «белый стих». Безусловно, все эти сложные поэтические стихотворные формы требуют от поэтов-переводчиков определённые знания и подготовки. Форма стихотворения нередко оказывается определяющей, она тесно связана со смыслом, а в переводе, при вынужденной трансформации и даже при чётком соблюдении формы, смысл так или иначе теряется, не будучи наложен на поэтическую традицию. О роле и значении поэтических жанров в переводческом деле, не зря и не случайно, говорил с пафосом и нескрываемой гордостью легендарный литературовед, доктор филологических наук, профессор Азиз Шариф на Всемирном совещании переводчиков в Москве ещё в 1966 г.: «Когда же вопрос этот касается поэзии стран Востока, следует помнить о чрезвычайном богатстве, разнообразии и устойчивости поэтических форм, существующих и сохраняющих силу своего обаяния на протяжении веков, а то и тысячелетий» [8].

Одной из самых сложных, но весьма важных проблем художественного перевода, вообще, является владение языком оригинала. За исключением нескольких переводчиков азербайджанцев Владимира Кафарова, Сиявуша Мамедзаде, Аллы Ахундовой, Мансура Векилова, Илхама Бадалбейли, Азера Мустафазаде, Натига Расулзаде и др. - все остальные переводчики азербайджанской литературы из-за незнания языка, переводили не с оригинала, а с подстрочного текста, и, к сожалению, эта тенденция продолжается поныне. Существует множество рассуждений о целесообразности подготовки более высокого уровня подстрочных текстов, с обширными разъяснениями и комментариями, для помощи переводчикам, незнающим язык оригинала. А может не стоит так обострять проблемы и пойти по простому европейскому пути в переводческом деле: добротно, обстоятельно, с точностью, с разъяснениями переводить художественные тексты на русский язык, лишь для информационной 
трансформации, оставляя за бортом образность, художественное мышление, да и всю гамму эстетической информации оригинала?! Но, на наш взгляд, это слишком было бы упрощенческим, разрушительным и неверным подходом к монументальному храму сокровищниц советской переводческой школы, в создании которой, без исключения, участвовали все творцы художественного слова, по мере возможности своих талантов, всех народов некогда Великой Страны.

Опытный переводчик-практик и теоретикпереводовед Ирина Алексеева точно определяла необходимость художественных текстов в жизни человека: «Для чего нам нужны художественные тексты? Может быть, это излишество? Ведь никаким практическим задачам они не служат. Но мы читаем их, мы тянемся к ним, а некоторые люди и дня без них прожить не могут. <..> Художественные тексты живут веками. И люди постоянно возвращаются к ним. Возвращаются к Шекспиру, написавшему свои трагедии и сонеты четыреста лет назад, возвращаются к Гомеру, создавшему “Илиаду" и “Одиссею” тридцать веков назад. Почему? А потому что, чтение художественных текстов может быть удовольствием, изысканным наслаждением, доступным только человеку. И человек не устаёт себе это наслаждение доставлять. Оказывается, художественная литература - это тексты, специализированные на передаче эстетической информации» [12, с. 131-132].

Видимо, для удовлетворения своих духовных потребностей, человечество всё равно веками неустанно продолжает переводить бессмертные образцы друг друга: и стихи, и прозу, и пьесу..., даже если гипотетически считать доказанным тезис о принципиальной «непереводимости» или «труднопереводимости» художественных текстов. Определённые общие проблемы, трудности и недосказанность смыслов, являясь творческим фактором в переводческом процессе, скорее всего, не отталкивает, а напротив, ещё сильнее притягивает переводчиков, направляя их к новым и новым, дальнейшим творческим поискам. Это естественно, народы мира не могут обойтись, не подпитывая друг друга духовноэстетическими, морально-культурными ценностями. Мы нуждаемся друг в друге, не из-за куска хлеба насущного, а в более возвышенной материи - духовной пище. Следовательно, одно из достояний современного цивилизованного общества - художественный перевод, как из важных духовно-моральных составляющих в повседневной жизни человечества будет востребован надолго, а может и вечно.

Вернёмся к конкретным фактическим материалам. В начале 1990-х гг. закончился советский период взаимодействия национальных культур и литератур. Известный прозаик, Народный писатель Азербайджана, доктор филологических наук, профессор Эльчин (1943 р.) размышляя о соцреализме, в одной своей интересной теоретической работе, сделал весьма любопытные, объективные выводы: «Одно из больших достижений периода соцреализма связано с переводной литературой. И при объективном взгляде на вопрос мы убедимся, что современная азербайджанская школа художественного перевода - детище соцреализма <...>. С другой стороны, были переведены на родной язык творения представителей азербайджанской литературы, писавших на арабском и на фарси (Хагани, Мехсети, Низами); одновременно и наша классическая и современная литература была переведена на иностранные языки» [13].

Несомненно, литературные контакты азербайджанского и русского народов, активный взаимообмен культурными ценностями всегда является взаимоперевод - конкретное выражение обогащения двух литератур. Как известно, в советский период весь процесс переводческой деятельности в стране, в основном, находился под контролем властей, происходил в плановом режиме, достаточно щедро оплачивался творческий труд не только автора оригинала, но и переводчиков. Благодаря такому государственному подходу смело можно утверждать, что в Советском Союзе переводческое дело развивалось, расцветало во всю мощь и поистине в глобальном масштабе послужило формированию единой многонациональной литературы, а также к сближению, взаимопониманию, взаимоуважению и сплочению всех народов, проживающих в стране. В те годы дружба народов была не клише пропаганды, а реальным достижением общности людей.

Приходится констатировать, что после распада Советского Союза наступившие времена более свободных, но и более бессистемных переводов постепенно проходят, и допущенные немалые изъяны «идут на поправку». Начало XXI в. вновь показывает примеры активного взаимоперевода с русского на азербайджанский язык и обратно. По этому поводу информация известного литературоведа Гейдара Оруджева кажется интересной: «Переводчики переводят не по заказу, а по своему выбору. При этом переводчики на азербайджанский язык обращаются к произведениям, которые в годы советской власти не были переведены. Так, уже переведены и изданы отдельные произведения М. Булгакова («Мастер и Маргарита»), А. Платонова и др. в Азербайджане» [14]. По эмоциональному замечанию профессора Тельмана Велиханлы: «Перевод и издание русской литературы в постсоветском Азербайджане набрал такие темпы, до которых никто не додумался бы раньше. В последние два десятилетия появи- 
лись поэтические сборники русских модернистов, поэтов серебряного века, были осуществлены новые переводы классической и современной русской поэзии <...> Перевод азербайджанской литературы, в том числе поэзии, на русский язык также оказался столь же плодотворным» [15].

Однако, известный писатель, литературовед, профессор Чингиз Гусейнов, придерживаясь полярного мнения, всё же подчёркивает положительные стороны переводческого дела в прежние времена: «Ныне переводческая школа переживает кризис, раньше это было, помимо всего прочего, и финансово-прибыльным занятием, и политически престижным делом» [16].

В журнале «Дружба народов» в 2012 г. был опубликован обширный материал круглого стола по проблемам художественного перевода национальных литератур. Высказывания заведующей отделом поэзии журнала «Литературный Азербайджан» Алины Талыбовой на этом литературном мероприятии кажутся несколько преувеличенными и противоречивыми, но, в основном, справедливыми: «Практически прекратила своё существование и школа художественного перевода. Сегодня у нас есть лишь небольшое число более или менее профессиональных литераторов, занимающихся попутно с собственным творчеством и разовыми переводами, а ведь перевод - искусство самоценное... Сложно понять, кого можно винить в сложившейся ситуации, ведь сегодня переводческий труд практически не оплачивается, а они пока ещё не научились питаться воздухом <...> А ведь русский язык в республиках бывшего СССР, в частности в Азербайджане, приобрётший новые стилистические и лексические оттенки, нередко был правильнее и выразительнее, чем в "метрополии" (тем более сегодняшней, с её криминально-маргинальным сленгом и компьютерным новоязом) <...> Уходит то самое двуязычие, свободное и естественное владение двумя и более языками, тончайшее и безошибочное чувство языка, лексики, стиля, отличавшее наших переводческих мэтров» [17]. Точно оценивает автор уровень новых низкопробных переводов, сделанных со слабых подстрочников: «Есть и “франкенштейны” от перевода, которые расчленяют подлинник, старательно подсчитывая количество слогов, глаголов и существительных, что в их собственных глазах является признаком профессионализма, но в итоге перед нами предстаёт очередной бездыханный стихотворный “труп”, совершенно непригодный для читательского восприятия» [17].
Московский азербайджанский поэт Валех Салех также считает проблему перевода одной из главных трудностей распространения современной азербайджанской литературы: «Проблемы перевода - это серьёзный вопрос, которым необходимо заниматься на государственном уровне: проводить тендеры на лучшие переводы, широко привлекать к работе издательства. Ведь сегодня авторы сами организовывают переводы, за определённую плату их печатают, своими силами занимаются продажей литературы. Приходится идти, к книготорговцам, чтобы твои книги выставили на продажу. По этой причине очень многие талантливые авторы пишут “в стол". <...> В Азербайджане тоже, к сожалению, не налажена система книжного бизнеса» [18].

Народный писатель Азербайджана Анар констатирует: «С распадом СССР в России интерес к иностранной литературе, я условно говорю, допустим, к таиландской литературе, - стал куда больше, чем к азербайджанской или грузинской литературе. Из ряда “советского зарубежья” мы выпали, а как “иностранную литературу" нас ещё не воспринимают» [19].

Только перевод способен вывести литературу с национального на межнациональный уровень, ввести её в контекст мирового пространства словесности. Как точно замечала профессор Ф.А. Велиханова, «именно сопоставление азербайджанской культуры с мировой ведёт к преодолению замкнутости национальных рамок, более широкому выходу к сопоставлению и оценке национальных литературных явлений» [20].

Несмотря ни на что, азербайджанско-русский взаимоперевод продолжается. И необходимо подчеркнуть, что писатели азербайджанцы-москвичи остаются одними из лучших представителей и носителей устоявшейся школы перевода советского и постсоветского периода, являясь в числе полноправных наследников многонациональной советской и постсоветской литературы. Московские азербайджанские писатели, находясь, во многом, в неразрывном контексте с современным русским языком, также не теряют связи с родным азербайджанским языком.

Современный художественный перевод, в том числе, азербайджанско-русского направления, остаётся орудием межкультурного общения и требует решения всё новых и новых творческих и организационных задач, для выполнения перемен в жанровых характеристиках современной прозы и поэзии, а также укрепления и развития межродовых связей литературы.

\section{Список литературы:}

1. Пашазаде И. Поэтические особенности русских переводов произведений Гусейна Джавида. Баку, 2013. С. 19.

2. Горький М. Собр. соч.: в 30-ти т. Т. 27. М.: Художественная литература, 1953. С. 296. 
3. Чуковский К.И. Высокое искусство. М.: Советский писатель, 1968. 384 с.

4. Фёдоров А.В. Основы общей теории перевода. М.: Наука, 1968. 348 с.

5. Məmməd Arif. Seçilmiş əsərləri, 3 cilddə, I cild, s. 341.620 səh.

6. Азимов Д.А. Основные принципы перевода с русского языка на азербайджанский язык: Автореф. дисс. ... канд. филол. наук. Баку, 1975. 21 с.

7. Гусейнова С.Г. Русские переводы произведений азербайджанских поэтесс (Мехсети Гянджеви, Хуршидбану Натаван, Нигяр Рафибейли, Мирварид Дильбази): Автореф. дисс. ... канд. филол. наук. Баку, 1992. 23 с.

8. Бабаева Н.Г. Национальное своеобразие современной азербайджанской поэзии в русских переводах: Дисс. ... канд. филол. наук. Баку, 1984. С. 6, 19.

9. Новрузов Р.М. Художественный перевод как форма межнациональных литературных взаимосвязей (на материале русской и азербайджанской литературы XIX века): Дисс. ... канд. филол. наук. Баку, 1983. 176 с.

10. Таирбеков Б.Г. Проблематика перевода как предмета переводоведения: Автореф. дисс. ... докт. филол. наук. Баку, $1973.48 \mathrm{c}$.

11. Велиханова Ф.А. Русские переводы поэзии Самеда Вургуна. Баку: Элм, 1968; Она же. Азербайджанская советская поэзия на русском языке. Баку: Элм, 1977. 195 с.

12. Алексеева И.С. Текст и перевод. Вопросы теории. М.: Международные отношения, 2008. С. 131-132, 135.

13. Эльчин. Что дал нам соцреализм? К постановке вопроса // Дружба народов. 2012. № 2. [Электронный ресурс] URL: http://magazines.russ.ru/druzhba/2012/2/e113-pr.html.

14. Оруджев Г. История перевода с азербайджанского языка на русский и обратно. [Электронный pecypc] URL: http:// www.translit.az/RU/ISTORIYAPER/rus\%20istoriya.htm.

15. Велиханлы Т. «Пусть покажется тот край, где родина моя живёт». [Электронный pecypc] URL: http://www.bsuhl. edu.az/meqale008.php.

16. Гусейнов Ч.Г. К вопросу о «русскости нерусских» // Дружба народов. 2014. № 4. [Электронный pecypc] URL: http:// magazines.russ.ru/druzhba/2014/4/21g.html.

17. Проблемы художественного перевода национальных литератур и развития гуманитарных отношений: круглый стол // Дружба народов. 2012. № 5. [Электронный ресурc] URL: http://magazines.russ.ru/druzhba/2012/5/p29.html.

18. Дети Азербайджана. [Электронный ресурс] URL: http://magazines.russ.ru/ra/otkliki/18.html.

19. Анар. «Я ведь писатель...» беседу вела Т. Бек // Вопросы литературы. 2002. № 6. [Электронный pecypc] URL: http:// magazines.russ.ru/voplit/2002/6/anar-pr.html.

20. Велиханова Ф.А. Азербайджан в единстве мирового культурного пространства. Сравнительное литературоведение. Баку, 2004. С. 40.

\section{References (transliterated):}

1. Pashazade I. Poeticheskie osobennosti russkikh perevodov proizvedenii Guseina Dzhavida. Baku, 2013. S. 19.

2. Gor'kii M. Sobr. soch.: v 30-ti t. T. 27. M.: Khudozhestvennaya literatura, 1953. S. 296.

3. Chukovskii K.I. Vysokoe iskusstvo. M.: Sovetskii pisatel', 1968. 384 s.

4. Fedorov A.V. Osnovy obshchei teorii perevoda. M.: Nauka, 1968. 348 s.

5. Məmməd Arif. Seçilmiş əsərləri, 3 cilddə, I cild, s. 341.620 səh.

6. Azimov D.A. Osnovnye printsipy perevoda s russkogo yazyka na azerbaidzhanskii yazyk: Avtoref. diss. ... kand. filol. nauk. Baku, 1975. $21 \mathrm{s.}$

7. Guseinova S.G. Russkie perevody proizvedenii azerbaidzhanskikh poetess (Mekhseti Gyandzhevi, Khurshidbanu Natavan, Nigyar Rafibeili, Mirvarid Dil'bazi): Avtoref. diss. ... kand. filol. nauk. Baku, 1992. 23 s.

8. Babaeva N.G. Natsional'noe svoeobrazie sovremennoi azerbaidzhanskoi poezii v russkikh perevodakh: Diss. ... kand. filol. nauk. Baku, 1984. S. 6, 19.

9. Novruzov R.M. Khudozhestvennyi perevod kak forma mezhnatsional'nykh literaturnykh vzaimosvyazei (na materiale russkoi i azerbaidzhanskoi literatury XIX veka): Diss. ... kand. filol. nauk. Baku, 1983.176 s.

10. Tairbekov B.G. Problematika perevoda kak predmeta perevodovedeniya: Avtoref. diss. ... dokt. filol. nauk. Baku, 1973.48 s.

11. Velikhanova F.A. Russkie perevody poezii Sameda Vurguna. Baku: Elm, 1968; Ona zhe. Azerbaidzhanskaya sovetskaya poeziya na russkom yazyke. Baku: Elm, 1977.195 s.

12. Alekseeva I.S. Tekst i perevod. Voprosy teorii. M.: Mezhdunarodnye otnosheniya, 2008. S. 131-132, 135.

13. El'chin. Chto dal nam sotsrealizm? K postanovke voprosa // Druzhba narodov. 2012. № 2. [Elektronnyi resurs] URL: http:// magazines.russ.ru/druzhba/2012/2/e113-pr.html.

14. Orudzhev G. Istoriya perevoda s azerbaidzhanskogo yazyka na russkii i obratno. [Elektronnyi resurs] URL: http://www. translit.az/RU/ISTORIYAPER/rus\%20istoriya.htm.

15. Velikhanly T. «Pust' pokazhetsya tot krai, gde rodina moya zhivet». [Elektronnyi resurs] URL: http://www.bsuhl.edu.az/ meqale008.php.

16. Guseinov Ch.G. K voprosu o «russkosti nerusskikh» // Druzhba narodov. 2014. № 4. [Elektronnyi resurs] URL: http:// magazines.russ.ru/druzhba/2014/4/21g.html.

17. Problemy khudozhestvennogo perevoda natsional'nykh literatur i razvitiya gumanitarnykh otnoshenii: kruglyi stol // Druzhba narodov. 2012. № 5. [Elektronnyi resurs] URL: http://magazines.russ.ru/druzhba/2012/5/p29.html.

18. Deti Azerbaidzhana. [Elektronnyi resurs] URL: http://magazines.russ.ru/ra/otkliki/18.html.

19. Anar. «Ya ved' pisatel'...» besedu vela T. Bek // Voprosy literatury. 2002. № 6. [Elektronnyi resurs] URL: http://magazines. russ.ru/voplit/2002/6/anar-pr.html

20. Velikhanova F.A. Azerbaidzhan v edinstve mirovogo kul'turnogo prostranstva. Sravnitel'noe literaturovedenie. Baku, 2004. S. 40 . 